\title{
Productividad de diez cultivares promisorios de papa chaucha (Solanum tuberosum, grupo Phureja) de la región Cajamarca
}

\section{Productivity of ten promising chaucha potato cultivars (Solanum tuberosum, Phureja group) in the Cajamarca region}

\author{
Luz P. Rojas Mercado; Juan F. Seminario Cunya* \\ Programa de Raíces y Tubérculos Andinos, Facultad de Ciencias Agrarias, Universidad Nacional de Cajamarca.
}

Recibido 31 julio 2014. Aceptado 17 octubre 2014.

\begin{abstract}
Resumen
Se evaluó la productividad de diez cultivares de papa chaucha de la Región Cajamarca, en Diseño de Bloques Completos al Azar, con diez tratamientos (cultivares) y tres repeticiones: Peruanita 3, Montañera 2, Limeña, Amarilla, Clavelina 2, Roja 2, Mulla, Huagalina, Amarilla mahuay y Chimbina colorada. Se evaluó altura de planta, número de tallos, número total de tubérculos, número de tubérculos comerciales, peso total de tubérculos, peso de tubérculos comerciales, materia seca de tubérculos, peso seco del follaje e índice de cosecha. El rendimiento varió de 5,0 (Huagalina) a 11,5 t ha ${ }^{-1}$ (Amarilla mahuay) con una media de 8,6 t ha ${ }^{-1}$. El peso total de tubérculos, el peso de tubérculos comerciales, el número total de tubérculos y el peso seco del follaje, presentaron diferencias estadísticas significativas entre cultivares. Los cultivares Limeña y Huagalina fueron estadísticamente inferiores al resto de cultivares, en peso total de tubérculos y peso de tubérculos comerciales. Se encontraron diferencias estadísticas altamente significativas para número de tallos e índice de cosecha. Los mejores índices de cosecha se registraron en Huagalina (46\%), Amarilla mahuay (45\%) y Clavelina $2(42 \%)$
\end{abstract}

Palabras clave: Papa nativa, diploide, rendimiento, índice de cosecha.

\begin{abstract}
The productivity of ten treatments (chaucha cultivars) with three replications, all from the Cajamarca Region, were evaluated in a Randomized Complete Block Design: Peruanita 3 Mountaineer 2 Limeña, Yellow, Clavelina 2 Red 2 Mulla, Huagalina, yellow and red Chimbina mahuay. Plant height, number of stems, number of tubers, number of commercial tubers, total weight of tubers, weight of commercial tubers, tuber dry matter, dry weight of foliage and harvest index were evaluated. The yield ranged from 5.0 (Huagalina) to 11.5 $\mathrm{t} \mathrm{ha}^{-1}$ (Yellow mahuay) with an average of $8.6 \mathrm{t} \mathrm{ha}^{-1}$. The total weight of tubers, weight of commercial tubers, total number of tubers and foliage dry weight, showed statistically significant differences between cultivars. The Limeña and Huagalina cultivars were statistically lower than the other cultivars regarding total weight of tubers and weight of commercial tubers. Highly significant differences for number of stems and harvest index were found. Best harvest index were recorded in Huagalina (46\%), Yellow mahuay (45\%) and Clavelina 2 $(42 \%)$.
\end{abstract}

Keywords: Native potato, diploid, yield, harvest index.

\section{Introducción}

Las papas conocidas en la región Cajamarca (Perú) como chauchas, pertenecen al grupo Phureja (de nueve grupos en total) (Huamán y Spooner, 2002; Huamán, 2008) con el enfoque del Código Internacional de Nomenclatura de Plantas Cultivadas (ICNCP). El nombre phureja o fureja deriva del Aymara y alude a su precocidad ( phureja $=$ temprana o precoz) . En el norte peruano, el término chaucha también significa temprano o precoz. El mismo nombre (chaucha) es aplicado a esta papa en Ecuador (Monteros et al., 2010) y Colombia, aunque el nombre más frecuente en este último país es papa criolla (Rodríguez et al., 2009; Piñeros, 2009).

DOI: 10.17268/sci.agropecu.2014.04.01

\footnotetext{
* Autor para correspondencia

E-mail: jfseminario@yahoo.es (J. Seminario).
} 
El grupo incluye principalmente a genotipos diploides y también tetraploides $\mathrm{y}$ triploides, que muestran ausencia o mínima dormancia y por lo general, presentan tubérculos brotados al momento de la cosecha (Ghislain et al., 2006; Huamán, 2008; Gómez, et al., 2012). Son precoces (3 a 4 meses), se cultivan entre los 2000 a $3400 \mathrm{msnm}$, se adaptan a días cortos, son altamente heterogéneos en la forma y tamaño de los tubérculos, de buena calidad culinaria, buena aceptación en el mercado para varios de sus cultivares. Dentro del grupo existe material valioso para requerimientos específicos del mejoramiento y ha sido motivo de estudios en varios aspectos: Resistencia a enfermedades como la rancha Phytophthora infestans (Trognitz et al., 2002, Constanzo et al., 2005; Ñustez et al., 2008; Balleteros et al., 2010; Tinjaca, 2010; Coca-Morante y Tolin-Tordoya, 2013, Gabriel et al., 2013), marchitez bacteriana - Ralstonia solanacearum (Sequeira y Rowe, 1969; Escallón et al., 2005; Virupaksh et al., 2012; Moslemkhani et al., 2012), rizoctoniasis Rhizoctonia solani (Bautista et al., 2007), valor nutritivo (Dobson et al., 2004; Campos et al., 2006; Bonierbale et al., 2007; Burgos et al., 2007; Burgos et al., 2009; Bonierbale et al., 2009; Lu et al., 2012), procesamiento (Rivera et al., 2003, Ligarreto y Suarez, 2003; Nustez et al., 2012; Quintero et al., 2012; Tinjaca et al., 2012; Zárate et al., 2012). También contiene material resistente a virus como PVX, PSV, PMV y PAV y tolerante a bajas temperaturas y calor (Estrada, 2000; Ochoa, 2001; Mosquera et al., 2008; Guzmán y Rodríguez, 2010).

Estas papas son apreciadas por el agricultor y por el consumidor de la ciudad. Se consumen especialmente en sopas y puré. Una de sus limitantes es su aparente baja productividad, en relación con las variedades mejoradas. Asimismo, es altamente perecible y pierde rápidamente su aptitud para el consumo, debido que los tubérculos brotan en pocos días y no se pueden almacenar como las otras papas. Sin embargo, en Colombia se han seleccionado clones con ligera dormancia y se exportan fritas, precocidas congeladas y en salmuera (Ligarreto y Suarez, 2003).

Los rendimientos de tubérculos del grupo son altamente variables. Se informan de rendimientos experimentales de $5 \mathrm{t} \mathrm{ha}^{-1}$ (Rodriguez et al., 2012) hasta cerca de $50 \mathrm{t}$ $\mathrm{ha}^{-1}$ (Santos, 2010). El promedio nacional en Colombia es de $10 \mathrm{t} \mathrm{ha}^{-1}$, en un área total, en ese país, de 8140 ha sembradas (Bonilla et al., 2009).

La caracterización de una colección de papa chaucha (grupo Phureja), proveniente de las provincias de Chota, Hualgayoc y Cajamarca, indicó la presencia de más de 40 cultivares (Seminario y Zarpán, 2011). Estos cultivares son altamente variables en el rendimiento total de tubérculos $(50$ a $477 \mathrm{~g}$ planta $^{-1}$ ), en tubérculos comerciales (71 a $381 \mathrm{~g} \mathrm{planta}^{-1}$ ) y en los componentes que contribuyen a este rendimiento (altura de planta, número de tallos, número de tubérculos, número y peso de tubérculos comerciales). También, mostraron importante variación en el contenido de materia seca $(18,4 \%$ a $26,5 \%)$. De este germoplasma, se seleccionaron 10 cultivares como promisorios por su capacidad de producción. Estos cultivares son el objeto de estudio de la presente investigación, en la cual se probó su capacidad productiva, bajo las condiciones del Valle de Cajamarca (2650 msnm).

\section{Materiales y métodos}

La investigación se desarrolló en el Servicio Silvo Agropecuario de la Universidad Nacional de Cajamarca (UNC), ubicado a $07^{\circ} 10^{\prime} 02^{\prime \prime}$ latitud Sur y $78^{\circ} 29^{\prime} 39^{\prime \prime}$ longitud Oeste, a $2670 \mathrm{msnm}$, en la región Quechua baja (clima templado seco). Se utilizaron diez cultivares de papa chaucha (Solanum tuberosum grupo Phureja), seleccionados dentro del germoplasma que mantiene el Programa de Raíces y Tubérculos Andinos de la UNC, cuyos nombres y procedencia se describen en la Tabla 1. 
Tabla 1

Cultivares de papa chaucha (grupo Phureja) usados en el ensayo y su procedencia

\begin{tabular}{lllll}
\hline Cultivar & Código & Localidad & Distrito & Provincia \\
\hline Limeña & Lim & Rojaspampa & Chota & Chota \\
Roja 2 & Roj2 & Bambamarca (mercado) & Bambamarca & Hualgayoc \\
Mulla & Mu & La Shita & Jesús & Cajamarca \\
Clavelina 2 & Clav2 & Bambamarca (mercado) & Bambamarca & Hualgayoc \\
Amarilla mahuay & Amm & Totora & Jesús & Cajamarca \\
Chimbina colorada & Chic & La Tranca & Jesús & Cajamarca \\
Amarilla & Am & Camino grande & Hualgayoc & Hualgayoc \\
Peruanita 3 & Per3 & Andamahuay & Cortegana & Celendín \\
Montañera 2 & Mon2 & La Locpa & Bambamarca & Hualgayoc \\
Huagalina & Hua & Casa hacienda & Hualgayoc & Hualgayoc \\
\hline
\end{tabular}

Tabla 2

Datos meteorológicos registrados durante el periodo de la investigación

\begin{tabular}{|c|c|c|c|c|c|c|c|}
\hline \multirow{2}{*}{ Variable } & \multicolumn{5}{|c|}{ Meses } & \multirow{2}{*}{$\bar{x}$} & \multirow{2}{*}{ SD } \\
\hline & Ago. & Set. & Oct. & Nov. & Dic. & & \\
\hline Precipitación (mm) & 2,6 & 19,0 & 83,0 & 120,0 & 58,9 & 61,4 & 47,57 \\
\hline Humedad relativa $(\%)$ & 57 & 62 & 67 & 66 & 62 & 62,8 & 3,96 \\
\hline Temperatura promedio $\left({ }^{\circ} \mathrm{C}\right)$ & 14,2 & 14,6 & 15,0 & 15,4 & 15,3 & 14,9 & 0,44 \\
\hline Brillo solar (Horas) & 8,7 & 5,8 & 4,7 & 5,6 & 6,3 & 6,22 & 1,34 \\
\hline
\end{tabular}

Fuente: Estación Meteorológica Augusto Weberbauer, Convenio UNC-SENAMHI (2012). SD = desviación estándar.

El experimento consistió de 10 tratamientos (cultivares) en diseño de Bloques Completamente Randomizados, con tres repeticiones (tres bloques). La siembra se hizo a distanciamientos de 0,90 m entre surcos y 0,40 entre plantas $(27778$ plantas $\left.\mathrm{ha}^{-1}\right)$. La unidad experimental consistió de un surco por cultivar, de 12 plantas y un tubérculo por golpe o sitio.

Las variables meteorológicas (promedio / mes) de la temporada (agosto-diciembre 2012) en que se realizó el experimento se presentan en la Tabla 2. Hubo escasez de agua en agosto y septiembre, por lo que se requirió aplicar riego. En los siguientes meses, el cultivo se mantuvo con lluvia. La temperatura diaria $\left(14,9^{\circ} \mathrm{C}\right)$ fue ligeramente superior al promedio histórico $\left(14^{\circ} \mathrm{C}\right)$ en el valle, favorable para el desarrollo del cultivo. La humedad relativa y el brillo solar estuvieron en los rangos esperados para la región (GRC, 2013).

El suelo donde se realizó el experimento fue de pH neutro $(6,5)$, textura arcillosa, con contenido medio de materia orgánica $(3,42 \%)$ y fósforo $(9,03 \mathrm{ppm})$, y alto contenido de $\mathrm{K}$ (325 ppm) (Estación Experimental Baños de Inca, INIA).

Se usó la fórmula de fertilización 140-1400 , de nitrógeno, fósforo y potasio, respectivamente. Las fuentes fueron úrea ( $46 \%$ de N) y superfosfato simple (20\% de $\mathrm{P}_{2} \mathrm{O}_{5}$ ). Todo el superfosfato y la mitad de la úrea se aplicaron a la siembra. La otra mitad de la úrea se aplicó a los 20 días después de la siembra. Además, se aplicó a la siembra, estiércol de cuy (Cavia porcellus) a razón de $5 \mathrm{t} \mathrm{ha}^{-1}$. El primer deshierbo-aporque se realizó a los 20 días después de la siembra y las plantas tenían entre 15 a $20 \mathrm{~cm}$ de altura. En lo sucesivo, el campo se mantuvo el campo libre de malezas. El segundo aporque se realizó a los 65 días después de la siembra.

Se presentó ataque de pulguilla (Epitrix sp.) y se controló con dos aplicaciones de Tifón 4E (órgano fosforado, Chlorpyrifos) en la primera y tercera semana después de la emergencia, a razón de $0,03 \mathrm{~L}$ por bomba mochila de $20 \mathrm{~L}$. Para controlar escarabajo de la hoja (Diabrotica undecimpuctata), mosca minadora 
(Liriomyza sp.) y trips (Frankiliniella sp.), que se presentaron en pleno periodo vegetativo, se aplicó Monofos (Metamidophos) a razón de 2,0 $\mathrm{mL}$ por litro de agua. Como tratamiento preventivo contra la rancha (Phytophthora infestans) se hicieron dos aplicaciones de Ridomil 68 WP (Mancozeb; Metalaxil - M), a razón de 2,5 g por litro de agua.

La cosecha se realizó a los 132 días después de la siembra cuando todos los cultivares mostraron signos de madurez y los tubérculos no desprendían su piel ante la fricción con los dedos. Se cosecharon 10 plantas por tratamiento (cultivar) y por bloque. Se descartaron las plantas de los extremos de cada tratamiento, para evitar el efecto de borde (Vásquez, 2013).

Se evaluó altura de planta $(\mathrm{cm})$, número de tallos por planta, peso total de tubérculos $(\mathrm{g})$, peso de tubérculos comerciales $(\mathrm{g})$ (con diámetro superior a $2,5 \mathrm{~cm}$ ), número total de tubérculos, número de tubérculos comerciales, peso seco del follaje (g) y materia seca de los tubérculos (\%). Esta se determinó tomando dos tubérculos muestra de cada cultivar, se raspó la piel y se cortaron en rodajas finas. Luego se colocaron en estufa a $75^{\circ} \mathrm{C}$ por 72 horas y se aplicó la relación (Peso seco / Peso fresco) $x$ 100. El índice de cosecha $o$ coeficiente de partición se calculó mediante la fórmula: (peso seco de los tubérculos/peso de biomasa total al momento de la cosecha, excluyendo raíces) x 100 (Gardner et al., 1985). El número de tallos por metro cuadrado se obtuvo relacionando el número promedio de tallos por planta con el área ocupada por la planta en campo $\left(0,36 \mathrm{~m}^{2}\right)$. El rendimiento de tubérculos por planta y por surco se transformó a toneladas por hectárea.

El análisis de los datos se realizó tomando en consideración que el rendimiento, expresado como peso total de tubérculos por planta, depende de los componentes: número de plantas cosechadas, número total de tubérculos, número de tubérculos comerciales, peso de tubérculos comerciales, altura de planta, numero de tallos, peso seco del follaje, contenido de materia seca en los tubérculos, e índice de cosecha. Hay y Walker (1989) dicen que el rendimiento de la papa tiene tres componentes básicos de modo que: Peso seco de tubérculos (o rendimiento de peso fresco) $=$ Densidad de población de plantas $\mathrm{x}$ Número de tubérculos por planta x Peso promedio del tubérculo (o peso fresco). Pero la densidad de población también puede expresarse como número de tallos por área y en este caso el segundo componente debe expresarse como número de tubérculos por tallo. Para cada variable se realizó el análisis de varianza (ANOVA) y de acuerdo a la significación entre tratamientos se realizó la prueba de rango múltiple de Duncan. Se realizaron correlaciones estadísticas entre la variable dependiente PTT y los componentes del rendimiento. Enseguida, de acuerdo a la tendencia de la nube de datos se realizó el análisis de regresión correspondiente.

\section{Resultados y discusión}

\section{El rendimiento de tubérculos y sus componentes}

El ANOVA para las variables en estudio (Tabla 3) indicó que existe diferencia estadística significativa entre tratamientos (cultivares) para peso total de tubérculos (PTT), peso de tubérculos comerciales (PTC), número total de tubérculos (NTT), número de tubérculos comerciales (NTC), materia seca de los tubérculos (MST) (\%) y materia seca del follaje (PSF). Asimismo, existen diferencias altamente significativas para número de tallos (NT) y el índice de cosecha (IC). Tratándose de cultivares con características morfológicas $\mathrm{y}$ procedencias diferentes, se esperaba diferencias estadísticas en el rendimiento y las variables que contribuyen al mismo. Los trabajos realizados en Colombia, con clones seleccionados indican igualmente alta variación en el rendimiento de tubérculos y las variables asociadas (Escallón et al., 2005; Pérez et al., 2008; Rodríguez et al., 2009). 
Tabla 3

Cuadrados medios y significación del ANOVA, para el peso total de tubérculos por planta (PTT) y sus componentes de 10 cultivares promisorios de papa chaucha (grupo Phureja) de Cajamarca

\begin{tabular}{lcccccccccc}
\hline FV & GL & PTT & PTC & NTT & NTC & AP & NT & MST & PSF & IC \\
\hline Bloque & 2 & $123585,21 N S$ & $61633,18^{* *}$ & $3,58^{* *}$ & $1,88^{* *}$ & $171,43 \mathrm{NS}$ & $0,067 \mathrm{NS}$ & $0,08 \mathrm{NS}$ & $9694,44 \mathrm{NS}$ & $7,71^{* *}$ \\
Cultivares & 9 & $25310,01^{*}$ & $10675,51^{*}$ & $1,05^{*}$ & $0,13 \mathrm{NS}$ & $120,89 \mathrm{NS}$ & $0,15^{* *}$ & $0,04 \mathrm{NS}$ & $27124,83^{*}$ & $2,21^{* *}$ \\
$\begin{array}{l}\text { Error } \\
\text { Total }\end{array}$ & 18 & 8678,14 & 3140,71 & 0,36 & 0,08 & 78,26 & 0,02 & 0,06 & 9837,55 & 0,22 \\
CV & & & & & & & & & & \\
\end{tabular}

FV $=$ Fuentes de variación, GL $=$ Grados de libertad, PTT $=$ Peso total de tubérculos $(\mathrm{g})$, PTC $=$ Peso de tubérculos comerciales $(\mathrm{g}), \mathrm{NTT}=$ Número total de tubérculos, NTC $=$ Número de tubérculos comerciales, AP = Altura de planta $(\mathrm{cm})$, $\mathrm{NT}=$ número de tallos, MST = Materia seca de tubérculos (\%), PSF = Peso seco de follaje (g), IC = índice de cosecha $(\%)$.

*Significativo, ** Altamente significativo, NS = no significativo.

La prueba de rango múltiple de DUNCAN, para las variables que mostraron diferencias estadísticas entre cultivares se presenta en la Tabla 4. Los cultivares Amarilla mahuay, Roja 2 y Chimbina colorada, son significativamente superiores en el PTT a Limeña y Huagalina. Pero a la vez, no son significativamente diferentes con el resto de cultivares, respecto a esta variable. Amarilla mahuay es significativamente superior a Limeña y Huagalina en el peso de tubérculos comerciales (PTC). Con el resto son similares. Los cultivares Roja 2, Amarilla, Mulla, Chimbina colorada y Peruanita 3, son significativamente superiores en el NTT a Limeña y Huagalina. El resto son estadísticamente semejantes a las primeras.

En NT, Huagalina es significativamente superior a los demás cultivares, excepto a Limeña, Mulla y Peruanita 3. Por otro lado, Limeña, Mulla y Peruanita son superiores a Momntañera 2, Amarilla mahuay, Roja 2, Chimbina colorada y
Amarilla. Asimismo, Clavelina 2, Montañera 2, Amarilla mahuay y Roja 2, son superiores a Amarilla. En PSF, Roja 2 y Mulla son significativamente superior a Amarilla mahuay, Clavelinaa 2 y Huagalina. El resto no muestran diferencias significativas para este carácter. Finalmente, la Tabla 5 muestra que Huagalina, Clavelina 2 y Amarilla mahuay son significativamente superiores al resto de cultivares en cuanto al IC. Además, Peruanita 3, Amarilla, Mulla, Limeña y Chimbina colorada son superiores a Roja 2 y Montañera 2, respecto a esta variable.

Las diferencias entre cultivares en las variables en estudio indican el potencial del germoplasma para el mejoramiento genético y agronómico, de modo que se puede seleccionar los materiales más productivos o formar compuestos clonales, agrupándolos por ciertas características generales como la forma del tubérculo (redondos, alargados) y el color de la pulpa (amarilla, blanca).

\section{Tabla 4}

Prueba de rango múltiple de DUNCAN para las variables que mostraron diferencias estadísticas entre cultivares de papa chaucha (grupo Phureja) de Cajamarca

\begin{tabular}{|c|c|c|c|c|c|c|c|c|c|c|c|c|c|c|c|c|c|c|c|c|}
\hline \multicolumn{4}{|c|}{ Cultivar PTT (g) } & \multirow{2}{*}{\multicolumn{2}{|c|}{$\frac{\text { PTC }(\mathrm{g})}{314,5 \mathrm{~A}}$}} & \multicolumn{3}{|l|}{ NTT } & \multicolumn{5}{|l|}{ NT } & \multicolumn{3}{|l|}{ PSF $(g)$} & \multicolumn{4}{|l|}{$\mathrm{IC}(\%)$} \\
\hline $\mathrm{Amm}$ & $475,2 \mathrm{~A}$ & & & & & 14,9 & A & B & 4,0 & & $\mathrm{C}$ & $\mathrm{D}$ & $E$ & 140,9 & B & $\mathrm{C}$ & $45 \mathrm{~A}$ & & & \\
\hline Roj2 & $463,3 \mathrm{~A}$ & & & $163,8 \mathrm{~A}$ & B & 23,6 & A & & 4,0 & & $\mathrm{C}$ & D & E & $350,0 \mathrm{~A}$ & & & 26 & & $\mathrm{C}$ & D \\
\hline Chic & $438,7 \mathrm{~A}$ & & & $226,3 \mathrm{~A}$ & B & 20,9 & A & & 4,0 & & & D & E & $284,0 \mathrm{~A}$ & B & & 28 & B & $\mathrm{C}$ & D \\
\hline $\mathrm{Mu}$ & $401,7 \mathrm{~A}$ & B & & $199,8 \mathrm{~A}$ & B & 20,6 & A & & 5,0 & B & $\mathrm{C}$ & & & $339,0 \mathrm{~A}$ & & & 23 & B & $\mathrm{C}$ & \\
\hline r3 & $393,0 \mathrm{~A}$ & B & $\mathrm{C}$ & $197,2 \mathrm{~A}$ & $\mathrm{E}$ & 20,6 & A & & 5,0 & B & $\mathrm{C}$ & D & & $4 \mathrm{~A}$ & B & $\mathrm{C}$ & 32 & B & & \\
\hline Mon2 & $337,8 \mathrm{~A}$ & B & $\mathrm{C}$ & $8 \mathrm{~A}$ & $\mathrm{E}$ & 17,4 & A & B & 4,0 & & $\mathrm{C}$ & $\mathrm{D}$ & E & $6 \mathrm{~A}$ & B & & 22 & & & D \\
\hline $\mathrm{Am}$ & $333,0 \mathrm{~A}$ & B & C & $50,8 \mathrm{~A}$ & $\mathrm{E}$ & 21,0 & A & & 3,0 & & & & E & $231,8 \mathrm{~A}$ & B & $\mathrm{C}$ & 28 & B & $\mathrm{C}$ & \\
\hline Clav2 & $314,4 \mathrm{~A}$ & B & $\mathrm{C}$ & $157,2 \mathrm{~A}$ & B & 14,2 & A & B & 4,0 & & & $\mathrm{D}$ & E & 117,8 & B & $\mathrm{C}$ & $42 \mathrm{~A}$ & & & \\
\hline Lim & 225,7 & & $\mathrm{C}$ & 118,0 & $\mathrm{E}$ & 10,5 & & B & $6,0 \mathrm{~A}$ & B & & & & $181,8 \mathrm{~A}$ & B & $\mathrm{C}$ & 24 & B & $\mathrm{C}$ & D \\
\hline Hua & 213,0 & & $\mathrm{C}$ & 104,9 & B & 9,5 & & B & $7,0 \mathrm{~A}$ & & & & & 69,8 & & $\mathrm{C}$ & $46 \mathrm{~A}$ & & & \\
\hline
\end{tabular}

Medias con la misma letra no son significativamente diferentes. El significado de las abreviaturas es el mismo que en la Tabla 3. Cada dato es el promedio de 30 observaciones (10 por tratamiento). 


\section{La productividad y variables asociadas}

Los cultivares en estudio mostraron alta variación en el PTT: $213 \mathrm{~g}$ planta $^{-1}$ (Huagalina) a $475 \mathrm{~g}$ planta $^{-1}$ (Amarilla mahuay). Estos valores corresponden a rendimientos de 5 a $11,5 \mathrm{t} \mathrm{ha}^{-1}$, como se observa en la Fig 1. Es destacable la superioridad de los cultivares Amarilla mahuay $\left(11,5 \pm 2,7 \mathrm{t} \mathrm{ha}^{-1}\right)$, Roja $2(10,9 \pm$ $\left.6,5 \mathrm{t} \mathrm{ha}^{-1}\right)$ y Chimbina colorada $(10,5 \pm 4,5$ $\left.\mathrm{t} \mathrm{ha}^{-1}\right)$. También es notable la alta variación de los cultivares, mostrada por la SD (barra vertical). Esta característica puede explicarse porque se trata de cultivares tradicionales, mantenidos por los agricultores, no uniformizados por el mejoramiento genético moderno.

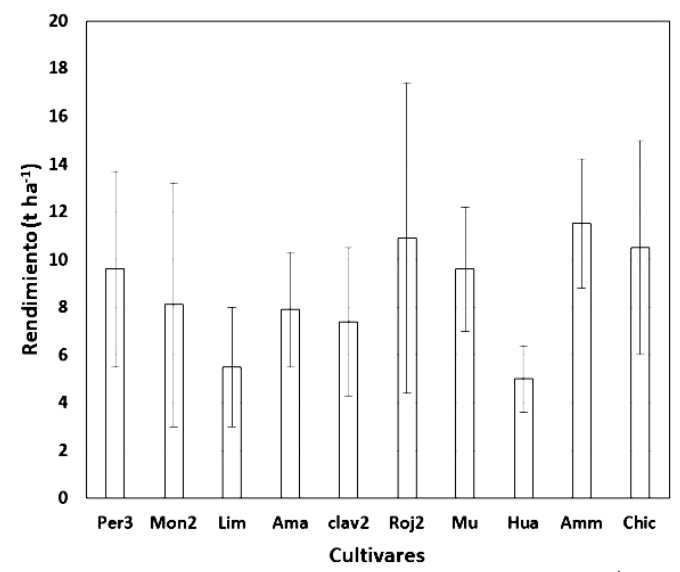

Figura 1. Rendimiento de tubérculos $\left(\mathrm{t} \mathrm{ha}^{-1}\right)$ de 10 cultivares de papa chaucha (grupo Phureja) de Cajamarca (la barra vertical indica la desviación estándar, SD).

Los rendimientos obtenidos son inferiores a los informados por Seminario y Medina (2009), con materiales de la misma región, aunque están dentro del rango esperado en el grupo Phureja. En los estudios previos, el grupo se muestra altamente variable $(2,6$ a 49,6 t ha ${ }^{-1}$ ) (Escallón et al., 2005; Santos, 2010). Sin embargo, la mayoría de resultados previos, indican rendimientos mayores de $10 \mathrm{t} \mathrm{ha}^{-1} \mathrm{y}$ menores de $20 \mathrm{tha}^{-1}$ (Muñoz y Lucero, 2008; Pérez et al., 2008; Rodríguez et al., 2009; Rodríguez et al., 2012). En este rango se ubican también, los rendimientos de parcelas comerciales en Colombia (Bonilla et al., 2009). En
Ecuador, se informa de rendimientos en la proporción de peso de tubérculos sembrados/peso de tubérculos cosechados de 1:3 a 1:10 (Monteros et al., 2010) y de 1,1 a 1,3 kg planta ${ }^{-1}$ (Martínez, 2009).

Nuestros datos y los precedentes, permiten inferir que el grupo Phureja no es altamente productivo, pero su relativo bajo rendimiento lo compensa con la calidad, su aceptación y los precios en el mercado, siempre superiores a los de la mayoría de papas. Por otro lado, la alta variación indica el potencial del grupo para el mejoramiento genético y la posibilidad de elevar los rendimientos, manipulando los multifactores agronómicos que intervienen en la cosecha.

Es necesario continuar los estudios sobre productividad bajo diferentes tratamientos agronómicos y ambientales. Por ejemplo, se debe probar el efecto de la época de aplicación y la fuente del fertilizante nitrogenado, considerando que son cultivares precoces. También son necesarios estudios sobre densidad de plantación y tamaño del tubérculo semilla. El peso promedio de los tubérculos (PTT/NTT) varió de 15,9 g (Amarilla) a 31,9 g (Amarilla mahuay). El peso de los tubérculos comerciales varió de 105,0 g (Huagalina) a 315,0 g (Amarilla mahuay). Destacaron en peso de tubérculos comerciales, además de A. mahuay, Montañera $2(76,0 \mathrm{~g})$ Clavelina $2(71,5 \mathrm{~g})$ y Mulla $(68,9 \mathrm{~g})$.

Los IC fueron bajos (22\% a $46 \%$ ), en comparación con reportes previos. Una explicación es que, si bien, al momento de cosecha los tubérculos estaban maduros, parte del follaje estaba verde y con el área foliar activa. Santos (2010), en cuatro variedades del grupo Phureja, encontró valores de $67 \%$ a $73 \%$ en localidad alta (2859 msnm) y $51 \%$ a $66 \%$ en localidad baja (2572 msnm). En variedades mejoradas de $S$. tuberosum (Betina, Pastusa suprema, Esmeralda y Diacol capiro) se encontraron IC de $71 \%$ a $85 \%$ (Ñustez et al., 2009). Gardner et al. (1985) y Hay y Walker (1989) sostienen que el IC 
tiene un coeficiente alométrico relativamente alto. Es decir, existe alta correlación entre peso de tubérculos y peso total de la planta. Asimismo, indican que el IC es un parámetro estable (para tuberosas y cereales) en tiempo y en espacio, para cada cultivar. Se ha sugerido que el IC y la tasa fotosintética son los dos factores esenciales en el rendimiento, pero el primero tendría mayor potencial para el incremento de la cosecha (Nustez et al., 2009), probablemente, debido a que se puede mejorar mediante prácticas agronómicas que conduzcan a una mayor asignación de la materia seca hacia los tubérculos.

En papa no es común evaluar el peso seco de los tubérculos y del follaje, pero se recomienda hacerlo, debido a que el peso fresco no es una buena variable. Por ejemplo, un valor alto puede ser expresión de mayor cantidad de agua en los tejidos. En cambio, el IC es una relación estable porque relaciona pesos secos. Sin embargo, debe tomarse en cuenta que el IC evaluado al final del ciclo, cuando las plantas están en senescencia natural, tiene el inconveniente de que parte de la materia seca de la parte aérea se ha perdido por caída y descomposición (Hay y Walker, 1989). En este sentido, es necesario evaluar el IC, de la forma sugerida por Kohashi et al. (1980). Los autores, plantearon una modificación al IC convencional (que toma en cuenta el rendimiento biológico en pie, o sea al momento de la cosecha) al que llamaron índice de cosecha modificado ( $\mathrm{ICm}$ ). Su evaluación implica el recojo de las partes senescentes, que van cayendo en el transcurso del ciclo de la planta.

Los cultivares mostraron entre 8 (Amarilla) a 19 (Huagalina) tallos $\mathrm{m}^{-2}$. Este aspecto debe ser explorado mediante investigaciones sobre densidad de plantación, considerando que el número de tubérculos por planta y por metro cuadrado depende del número de tallos principales por planta. Asimismo, el número de tallos está estrechamente relacionado con el tamaño de los tubérculos y la densidad de plantación (van der Zaag et al., 1990; Masarirambi et al., 2012). Para papas en general se ha sugerido que 20 a 25 tallos $\mathrm{m}^{-2}$ puede ser recomendable (van der Zaag, 1992) y en una variedad precoz (90 a 105 días) de $S$. tuberosum se encontró que la mejor producción se obtiene con 21 tallos $\mathrm{m}^{-2}$ y siembra a $0,90 \mathrm{~m} \times 0,30 \mathrm{~m}$, entre surcos y plantas, respectivamente (Masarirambi et al., 2012).

\section{Comportamiento de otras variables}

El número de tubérculos comerciales (NTC) (Tabla 5) varió de 2 (Huagalina) a 4,2 (Chimbina colorada). Sin embargo, el porcentaje de tubérculos comerciales en relación al total de tubérculos fue de $13 \%$ (Roja 2) hasta 25\% (Amarilla mahuay). Los cultivares mostraron pesos promedio de tubérculos comerciales (PTC/NTC) superiores a los $40 \mathrm{~g}$, con diámetros superiores a $3 \mathrm{~cm}$ (Tabla 5). Es decir, se ubicaron dentro de las categorías primera y segunda, según la clasificación para tubérculos de esta papa en Colombia (Escallón et al., 2005; Perez et al., 2008; Rodríguez et al., 2009).

La altura de planta varió de $60,7 \mathrm{~cm}$ (Huagalina) a 80,2 cm (Mulla) (Tabla 5), sin diferencias estadísticas entre cultivares. Se confirma el tamaño pequeño del grupo. En selecciones clonales de Colombia se reportan promedios de $86,2 \mathrm{~cm}$ y en cruces de $S$. phureja x $S$. goniocalyx (otra especie de tamaño pequeño) se informa valores de 91 a $102 \mathrm{~cm}$ de altura (Rodríguez et al., 2009).

Los promedios de materia seca de los tubérculos (MST) (Tabla 5) variaron de 24\% (Montañera 2) hasta 28\% (Huagalina) sin diferencias estadísticas entre cultivares. Estos valores se ubican dentro del rango informado en estudios previos. Pérez et al. (2008) en la variedad Criolla Colombia encontraron $26 \%$ a $28 \%$, con diferencias por la aplicación de manganeso al suelo ( 3 $\mathrm{kg} \mathrm{ha}{ }^{-1}$ y $0 \mathrm{~kg} \mathrm{ha}^{-1}$, respectivamente). Ligarreto y Suarez (2003) en 50 accesiones colombianas encontraron de $16 \%$ a $28 \%$ de MST, con una media de $21 \%( \pm 2,06)$. Por 
otro lado, Zárate et al. (2012) en 17 clones colombianos encontraron de $19 \%$ a $28 \%$ de MST.

\section{Tabla 5}

Número de tubérculos comerciales (NTC), diámetro de tubérculos comerciales (DT), altura de planta (AP) y materia seca de los tubérculos (MST) de 10 cultivares de papa chaucha (grupo Phureja) de Cajamarca

\begin{tabular}{lcccc}
\hline Cultivar & NTC & $\begin{array}{c}\text { DT } \\
(\mathrm{cm})\end{array}$ & $\begin{array}{c}\text { AP } \\
(\mathrm{cm})\end{array}$ & $\begin{array}{c}\text { MST } \\
(\%)\end{array}$ \\
\hline Per3 & 3,4 & 3,5 & 72,8 & 25,1 \\
& 1,7 & 0,40 & 3,8 & 1,0 \\
Mon2 & 2,4 & 3,8 & 67,1 & 24,1 \\
& 2,1 & 0,33 & 17,1 & 1,7 \\
Lim & 2,2 & 4,0 & 73,6 & 24,9 \\
& 1,2 & 0,04 & 11,9 & 3,9 \\
Am & 3,2 & $4-0$ & 73,7 & 27,0 \\
& 2,4 & 0,05 & 6,7 & 0,4 \\
Clav2 & 2,2 & 3,0 & 70,3 & 26,7 \\
& 0,3 & 0,3 & 2,7 & 1,2 \\
Roj 2 & 3,0 & 4,0 & 79,1 & 26,0 \\
& 2,3 & 0,32 & 15,5 & 5,4 \\
Mu & 2,9 & 3,6 & 80,2 & 25,8 \\
& 1,0 & 0,45 & 4,9 & 1,4 \\
Hua & 2,0 & 3,0 & 60,7 & 28,1 \\
& 1,3 & 0,20 & 1,8 & 0,2 \\
Amm & 3,7 & 5,0 & 81,9 & 24,3 \\
& 0,7 & 0,40 & 9,2 & 1,2 \\
Chic & 4,2 & 4,5 & 70,6 & 25,7 \\
& 2,1 & 0,30 & 3,0 & 3,6 \\
\hline
\end{tabular}

Cada dato es el promedio 30 observaciones (10 por tratamiento). El número en la parte inferior de cada promedio es la desviación estándar (SD).

\section{Correlaciones $y$ regresiones entre el rendimiento y sus componentes}

Se encontró correlación directa y positiva entre algunas variables y el rendimiento de tubérculos expresado como peso total de tubérculos (PTT) (Tabla 6). La tendencia de la nube de datos y la línea de regresión indicó relaciones de regresión lineal simple entre variables. $\mathrm{Al}$ correlacionar NTT con PTT, se comprobó alta correlación entre estas variables $(\mathrm{r}=$ 0,75). El coeficiente de regresión (b) indicó que por cada unidad de incremento de la variable NTT, el rendimiento (PTT) se incrementa en 14,3 unidades. Por otro lado, el valor del coeficiente de determinación $\left(\mathrm{r}^{2}=0,56\right)$ indicó que el $56,5 \%$ del rendimiento se explica por número total de tubérculos y el resto se explica por otras variables, no conocidas.

El NTC y el PTT presentaron alta correlación $(r=0,82)$. El coeficiente de regresión indicó que por cada unidad de incremento en el NTC, el PTT se incrementa en 106,3 unidades. Asimismo, el valor de $r^{2}=0,68$, implica que el $68,4 \%$ del rendimiento se explica por el NTC y el resto por otras variables desconocidas.

La correlación entre PTC y PTT fue alta ( $\mathrm{r}$ $=0,81)$. El coeficiente $\mathrm{b}$ indica que por cada unidad en que se incrementa el PTC, el rendimiento (PTT) se incrementa en 1,2 unidades. Por otro lado, el $\mathrm{r}^{2}=0,65$, implica que el $65,8 \%$ del PTT se explica por el PTC y el resto se explica por otras variables desconocidas. Las correlaciones y regresiones entre el rendimiento y sus componentes deben ser motivo de otros análisis en ensayos posteriores, porque permiten predecir el rendimiento en función de variables asociadas. Asimismo, el conocimiento de estas relaciones permite manipular mediante prácticas agrícolas las variables de interés agronómico (van der Zaag, 1992).

\section{Tabla 6}

Ecuaciones de regresión entre el peso total de tubérculos (PTT) y el número total de tubérculos (NTT), número de tubérculos comerciales (NTC) y peso de tubérculos comerciales (PTC)

\begin{tabular}{lcc}
\hline Variables & Ecuación regresión & $\mathrm{r}^{2}$ \\
\hline NTT vs PTT & $\mathrm{Y}=14,269 \mathrm{X}+112,62$ & 0,5651 \\
NTC vs PTT & $\mathrm{Y}=106,28 \mathrm{X}+48,593$ & 0,6842 \\
PTC vs PTT & $\mathrm{Y}=1,249 \mathrm{X}+132,81$ & 0,6582 \\
\hline
\end{tabular}

\section{Conclusiones}

La productividad de los diez cultivares de papa chaucha (grupo Phureja) de Cajamarca, en estudio, varió de 5,0 (Huagalina) a 11,5 $\mathrm{t} \mathrm{ha}^{-1}$ (Amarilla mahuay) con una media de $8,6 \mathrm{tha}^{-1}$.

Los cultivares Limeña y Huagalina fueron significativamente inferiores al resto de cultivares, desde el punto de vista 
productivo (peso total de tubérculos y peso de tubérculos comerciales).

Los mejores índices de cosecha se registraron en Huagalina (46\%), Amarilla mahuay (45\%), Clavelina $2(42 \%)$, con diferencias estadísticas significativas respecto al resto de cultivares.

Existe alta correlación estadística entre el peso total de tubérculos y las variables número total de tubérculos $(\mathrm{r}=0,75)$, número de tubérculos comerciales $(\mathrm{r}=$ $0,82)$ y peso de tubérculos comerciales $(\mathrm{r}=$ $0,81)$.

Estos resultados son indicios de la productividad del grupo Phureja en la región Cajamarca y en el Perú. Constituyen la base de otros estudios, necesarios para mejorar la producción, la conservación y el uso de este recurso, que por su biología (precoz y sin dormancia) puede ser vulnerable, a pesar de su buena calidad, aceptación en el mercado y otras bondades.

\section{Agradecimientos}

Al Dr. Víctor Vásquez por la revisión del análisis estadístico. A Segundo Julio Cusquisiban por su apoyo en el trabajo de campo. Al SENAMHI, Estación Augusto Weberbauer, por su colaboración con los datos meteorológicos. A Griselda Lay del Centro Internacional de la Papa, por su apoyo con artículos científicos.

\section{Referencias bibliográficas}

Ballesteros, D.C.; Gómez, G.; Delgado, M,C.; Álvarez, M,F.; Juyo, D.; Cuellar, D.; Mosquera, T. 2010. Posible presencia de un gen R1 en germoplasma de Solanum tuberosum grupo Phureja. Agronomía Colombiana 38: 137-146.

Bautista, G.; Mendoza, H.; Uribe, D. 2007. Biocontrol of Rhizoctonia solani in native potato (Solanum phureja) plants using native Pseudomonas flourescens. Acta biol. Colomb. 12: 19-32.

Bonierbale, M.; Amoros, W.; Burgos, G.; Salas, E.; Juarez, H. 2007. Prospects for enhancing the nutritional value of potato by plant breeding. African Potato Association Conference Proceeding 7: 24-46.

Bonierbale, M.; Grüneberg, W.; Amoros, W.; Burgos, G.; Salas, E.; Porras, E.; Zum Felde, T. 2009. Total and individual carotenoid profile in Solanum phureja of cultivated potatoes: II. Development and application of near-infrared reflectance spectroscopy (NIRS) calibrations for germplasm characterization. Journal of Food Composition and Analysis 22: 509-516.
Bonilla, M.H.; Cardozo, F.; Morales, A. 2009. Agenda prospectiva de investigación y desarrollo tecnológico para la cadena productiva de la papa en Colombia, con énfasis en papa criolla. Universidad Nacional de Colombia, CORPOICA. Ministerio de Agricultura y Desarrollo Rural. 174 p.

Burgos, G.; Amoros, W.; Morote, M.; Stangoulis, J.; Bonierbale, M. 2007. Iron and zinc concentration of native Andean potato cultivars from a human nutrition perspective. J. Sci. Food Agric. 87: 668-675.

Burgos, G.; Salas, E.; Amoros, W.; Auqui, M.; Muñoa, L.; Kimura, M.; Bonierbale, M. 2009. Total and individual carotenoid profiles in Solanum phureja of cultivated potatoes: I. Concentrations and relationships as determined by spectrophotometry and HPLC. Journal of Food Composition and Analysis 22: 503-508.

Campos, D.; Noratto, G.; Chirinos, R.; Arbizu, C.; Roca, W.; Cisneros-Zevallos, L. 2006. Antioxidant capacity and secondary metabolites in four species of andean tuber crops: native potato (Solanum sp.), mashua (Tropaeolum tuberosum Ruiz \& Pavon), oca (Oxalis tuberosa Molina) and ulluco (Ullucus tuberosus Caldas). Journal of the Science of Food and Agriculture 86: 1481-1488.

Coca-Morante, M.; Tolín-Tordoya, I. 2013. The Potato late blight caused by Phytophthora infestans Mont de Bary as selection factor of phurejas potatoes (Solanum phureja Juz et Buk) in endemic areas of the bolivian Andes. American Journal of Plant Sciences 4: 53-58.

Constanzo, S.; Simko, I.; Christ, B.J.; Haynes, K.G. 2005. QTL analysis of late blight resistance in a diploid potato family of Solanum phureja x S. stenotomum. Theor. Appl. Genet. 11: 609-617.

Dobson,G.; Griffiths, D.W.; Davies, H.V.; McNicol, J.W. 2004. Comparison of faty acid and polar lipid contents of tubers from two potato species, Solanum tuberosum and Solanum phureja. J. Agric. Food Chem. 52: 63066314.

Escallón, R.; Ramirez, M.; Ñustez, C.E. 2005. Evaluación del potencial de rendimiento y de la resistencia a Phytophthora infestans (Mont. De Bary) en la colección de papas redondas amarillas de la especie Solanum phureja (Juz. et Buk). Agronomía Colombiana 23: 35-41.

Estrada, N. 2000. La biodiversidad en el mejoramiento genético de la papa. Hardy, B y Martínez, E. (eds.). CIP, IPGRI, PRACIPA, IBTA, PROINPA, COSUDE, CID.La Paz, BOL. 372 p.

Gabriel, J.; Plata, G.; Cadima. X.; Franco, J. 2013. Solanum phureja Juz. et Buk.: Valuable source of genetic resistance to potato late blight (Phytophthora infestans (Mont.) de Bary. Revista Latinoamericana de la Papa 17: 131-141.

Gardner, F.P.; Pearce, R.B.; Mitchel, R.L. 1985. Physiology of crop plants. Iowa State University Press.

Ghislain, M.; Andrade, D.; Rodríguez, F.; Hijmans, R.; Spooner, D. 2006. Genetic analysis of the cultivated potato Solanum tuberosum L. Phureja Group using RAPDs and nuclear SSRs. Theor. Appl. Gent. 113: 1515-1527.

Gómez, T.M.; López, J.B.; Pineda, R.; Galindo, L.F.; Arango, R.; Morales, J.G. 2012. Caracterización citogenética de cinco genotipos de papa criolla, Solanum phureja (Juz. et Buk.). Rev. Fac. Agr. Medellín 65: 6379-6387. 
GRC (Gobierno Regional de Cajamarca). 2013. Humedad relativa multiannual (1981-2010) de la región Cajamarca. Sistema de Información Ambiental Regional (SIAR). Disponible en: siar.regioncajamarca.gob.pe

Guzmán, M.; Rodríguez, P. 2010. Suceptibility of Solanum phureja (Juz. Rt Buk.) to potato yellow vein virus. Agronomía Colombiana 28: 219-224.

Huamán, Z.; Spooner, D.M. 2002. Reclassification of landrace populations of cultivated potatoes (Solanum sect. Petota). American Journal of Botany 89: 947-965.

Huamán, Z. 2008. Descriptores morfológicos de las papa (Solanum tuberosum L.). Centro de Conservación de la Biodiversidad Agrícola de Tenerife, España. p. 34-35.

Hay, R.K.M.; Walker, A.J. 1989. An introduction to the physiology of crop yield. Longman scientific \& Technical. New York, USA.

Kohashi, J.; Carpio, J.; Miranda, S. 1980. Harvest index in Phaseolus vulgaris L. Ann. Rep. Bean Improv. Coop. 23: 87-89.

Ligarreto, G.A.; Suárez, M.N. 2003. Evaluación del potencial de los recursos genéticos de papa criolla (Solanum phureja) por calidad industrial. Agronomía Colombiana 21: 83-94.

Lu, W.; Yu, M.; Bai, Y.; Li, W.; Xu, X. 2012. Crude protein content in diploid hybrid potato clones of Solanum phureja - S. stenotomum. Potato Research 55: 315-322.

Martínez, F.A. 2009. Caracterización morfológica e inventario de conocimientos colectivos de variedades de papas nativas (S. tuberosum L.) en la provincia de Chimborazo. Tesis. Riobamba, ECU. Escuela de Ingeniería Agronómica, Facultad de Recursos Naturales, Escuela Superior Politécnica de Chimborazo. 207 p.

Masarirambi, M.T.; Mandisoza, F.C.; Mashingaidze, A.B.; Bhebhe, E. 2012. Influence of plant population and seed tuber size on growth and yield components of potato (Solanum tuberosum). International Journal of Agriculture \& Biology 14: 545-549.

Monteros, C.; Yumisaca, F.; Andrade, J.; Reinoso, I. 2010. Catálogo de cultivares de papas nativas. Sierra Centro Norte del Ecuador. Etnobotánico, morfológico, agronómico y calidad. Publicación miscelánea 176. INIAP, CIP, Papa Andina. 145 p.

Mosquera, T.; Fernández, C.; Martínez, L.; Acuña, A.; Cuéllar, D. 2008. Genética de la resistencia de la papa (Solanum tuberosum) a patógenos. Estado de arte. Agronomía Colombiana 26: 7-15.

Moslemkhani, K.; Mozafari, J.; Shams Bakhsh, M.; Mohamadi Goltape, E. 2012. Expressions of some defense genes against Ralstonia Solanacearum in susceptible and resistant potato genotypes under in vitro conditions. Iran. J. Plant Path. 48: 57-60.

Muñoz, L.A.; Lucero, A.M. 2008. Efecto de la fertilización orgánica en el cultivo de papa criolla Solanum phureja. Agronomía Colombiana 26: 340-346.

Nústez, C.E.; Santos, M.; Segura, M. 2009. Acumulación y distribución de materia seca de cuatro variedades de papa (Solanum tuberosum L.) en Zipaquirá, Cundinamarca (Colombia). Revista Facultad Nacional de Agronomía Medellín 62: 4823 - 4834.

Nustez, C.E.; Tinjaca, S.; Cotes, J.M. 2008. Respuesta a Phytophthora infestans en la colección del grupo Phureja de la Universidad Nacional de Colombia. En
Memorias XXIII Congreso de la Asociación Latinoamericana de la Papa y VI Seminario Latinoamericano de Uso y Comercialización de la Papa. 30 nov. a 6 diciembre 2008. Mar de Plata, Argentina. Pp.159-160.

Nustez, C.E.; Tinjaca, S.; Cotes J.M. 2012. Endulzamiento de genotipos de papa (S. phureja) en dos ambientes de almacenamiento. En XXV Congreso de la Asociación Latinoamericana de la Papa y XIV Encuentro Nacional de Producción y Abastecimiento de Batata. 17-20 de septiembre 2012. Uberlandia, BRA.

Ochoa, C.M. 2001. Las papas de Sudamérica. Bolivia. Instituto Francés de Estudios Andinos, Centro Internacional de la Papa. La Paz, Bolivia. 535 p.

Pérez, L.C.; Rodríguez, L.E.; Gómez, L.I. 2008. Efecto del fraccionamiento de la fertilización con $\mathrm{N}, \mathrm{P}, \mathrm{K}$ y Mg y la aplicación de los micronutrientes B, Mn y Zn en el rendimiento y calidad de papa criolla (Solanum phureja) variedad Criolla Colombia. Agronomía Colombiana 26: 477-486.

Piñeros, C.J. (Recop.). 2009. Recopilación de la investigación del sistema de papa criolla. Convenio SADE 045/06. Secretaría de Agricultura y Desarrollo Económico. Federación Colombiana de Productores de Papa. Colombia.

Quintero, M.A.; Mendoza, R.; Herrera, A.O. 2012. Efecto del procesamiento sobre el contenido de minerales en tres variedades de papa criolla (Solanum tuberosum grupo Phureja). En XXV Congreso de la Asociación Latinoamericana de la Papa y XIV Encuentro Nacional de Producción y Abastecimiento de Batata. 17-20 de septiembre 2012. Uberlandia, Brasil.

Rivera, J.E.; Herrera, A.; Rodríguez, L.E. 2003. Procesamiento de papa criolla precocida y congelada mediante la técnica de congelación individual (IQF), en seis genotipos promisorios de papa criolla (Solanum phureja). Agronomía Colombiana 21: 95-101.

Rodríguez, L.E.; Nustez, C.E.; Estrada, N. 2009. Criolla latina, Criolla paisa y Criolla Colombia, nuevos cultivares de papa criolla para el departamento de Antioquia (Colombia). Agronomía Colombiana 27: 289-303.

Rodríguez, L.E.; Tinjaca, R.S.; Cotes, J.M. 2012. Detección de QTLs asociados con potencial de rendimiento y dormancia en tubérculos en Solanum bukasovii x Solanum tuberosum grupo Phureja. En XXV Congreso de la Asociación Latinoamericana de la Papa y XIV Encuentro Nacional de Producción y Abastecimiento de Batata. 17-20 de septiembre 2012. Uberlandia, Brasil.

Santos, M. 2010. Evaluación del crecimiento, desarrollo y componentes de rendimiento de cuatro cultivares de papa criolla en dos localidades del departamento de Cundinamarca. Tesis Maestría, Facultad de Agronomía, Universidad Nacional de Colombia.

Seminario, J.; Medina, W. 2009. Diversidad de papa nativas en agroecosistemas tradicionales: Caso del distrito de Chota, Cajamarca. Fiat Lux 5: 5-24.

Seminario, J.; Zarpán, L. 2011. Conservación in situ on farm de Solanum tubersoum L. grupo Phureja en la cuenca del Llaucano y áreas adyacentes. Arnaldoa 18: 103-114.

Sequeira, L.; Rowe, P.R. 1969. Selection and utilization of Solanum phureja clones with high resistance to diferent strains of Pseudomonas solanacearum. American Potato Journal 46: 451-462. 
Tinjaca, S. 2010. Estudios de la heredabilidad de la resistencia horizontal a Phytophthora infestans (Mont.) de Bary causante de la "gota" en la especie diploide de papa Solanum phureja Juz. et Buk.. Tesis maestría. Medellín, Universidad Nacional de Colombia.

Tinjaca, S.; Rodríguez, L.E.; Cotes, J.M. 2012. Comportamiento del contenido de azúcares reductores en clones avanzados de papa diploide $S$. tuberosum Grupo andigenum (S. phureja). En XXV Congreso de la Asociación Latinoamericana de la Papa y XIV Encuentro Nacional de Producción y Abastecimiento de Batata. 17-20 de septiembre 2012. Uberlandia, Brasil.

Trognitz, F.; Manosalva, P.; Gysin, R.; Niño-Liu, D.; Simon, R.; Herrera, M.R.; Trognitz, B.; Ghislain, M.; Nelson, R. 2002. Plant defense genes associated with resistance to potato late blight in Solanum phureja $\mathrm{x}$ Dihaploid S. tuberosum hybrids. MPMI, 5 (6): 587 597. van der Zaag, P; Demagante, A.; Ewing, E. 1990. Influence of plant spacing on potato (Solaumn tuberosum L.) morphology, growth and yield under two contrasting environments. Potato research 33: 313-323.

van der Zaag, D.E. 1992. Potatoes and their cultivation in the Netherlands. Dutch Information Centre for Potatoes, Ministry of Agriculture and Fisheries Foregein Information Service. Netherlands.

Vásquez, V. 2013. Experimentación agrícola. Soluciones con SAS. 2 ed. CONCYTEC, Lima, Perú.

Virupaksh, U.; Patil, J.; Gopal, J.; Singh, B.P. 2012. Improvement for bacterial wilt resistance in potato by conventional and biotechnological approaches. Agric Res 1: 299-316.

Zárate, L.M.; Otalora, N.A.; Ramírez, L.M.; Garnica, A.M.; Prieto, L.; Ceron, M.S.; Argüelles, J.H. 2012. Extracción y caracterización de almidón nativo de clones promisorios de papa criolla (S. tuberosum grupo Phureja). Revista Latinoamericana de la Papa 18: 1-24. 